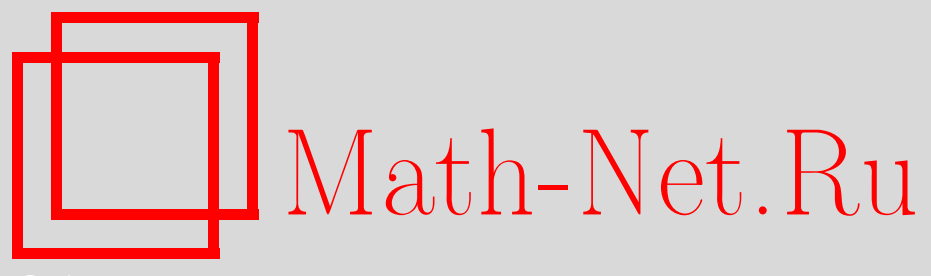

С. С. Кутателадзе, С. П. Новиков, Ю. Г. Решетняк, Александр Данилович Александров (к 100-летию со дня рождения), УМH, 2012, том 67, выпуск 5, 180-185

DOI: https://doi.org/10.4213/rm9491

Использование Общероссийского математического портала Math-Net.Ru подразумевает, что вы прочитали и согласны с пользовательским соглашением http://www . mathnet.ru/rus/agreement

Параметры загрузки:

IP : 52.23 .180 .231

26 апреля 2023 г., 16:33:47

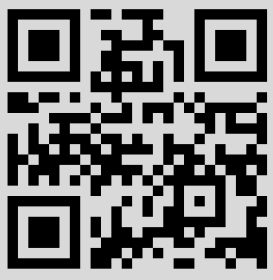




\section{Александр Данилович Александров}

(к 100-летию со дня рождения)

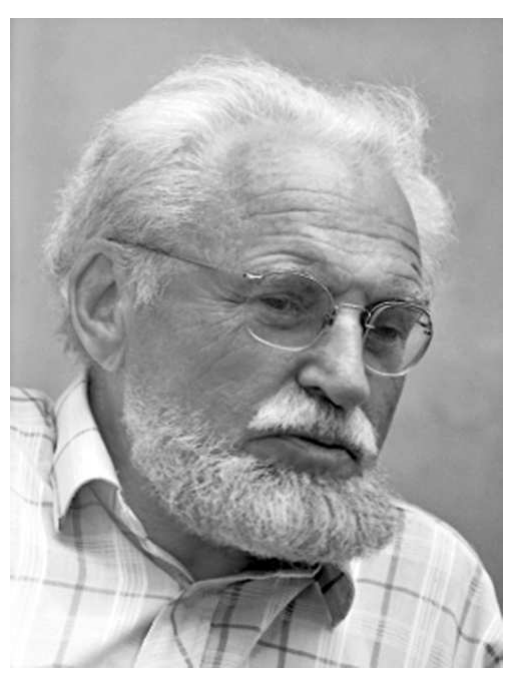

В классификаторе математических наук, составленном в 2010 г. совместно редакторами Mathematical Reviews и Zentralblatt für Mathematik, имеется раздел 53C45 Global surface theory (convex surfaces à la A.D. Aleksandrov). Такой чести среди русских геометров не удостоен даже Лобачевский. Александров стал первым геометром России XX века.

Александр Данилович Александров родился 4 августа 1912 г. в деревне Волынь бывшей Рязанской губернии. Его родители были учителями средней школы. В 1929 г. он поступил на физический факультет Ленинградского университета, который окончил в 1933 г. Наставниками Александрова стали Б.Н. Делоне (1890-1980) - выдающийся геометр и алгебраист, а также В. А. Фок (1898-1974) - один из крупнейших физиков-теоретиков прошлого века. Первые научные работы Александрова посвящены некоторым вопросам теоретической физики и математики. В дальнейшем основной специальностью Александрова стала геометрия. В 1935 г. Александров защитил кандидатскую, а в 1937 г. - докторскую диссертацию. В 1946 г. он был избран членом-корреспондентом, а в 1964 г. - действительным членом Академии наук СССР. С 1952 по 1964 г. Александров был ректором Ленинградского государственного университета. В эти годы он активно и эффективно поддерживал биологов в их борьбе с лысенкоизмом. В ЛГУ уже в те годы началось преподавание генетики, а в других университетах это произошло лишь в 1965 г. Александров активно поддержал социологию и математическую экономику подвергавшиеся остракизму властей. Александров пригласил на работу в университете выдающегося тополога В. А. Рохлина, до этого работавшего в провинциальных университетах, где его потенциал ученого и педагога не мог проявить себя в полном объеме. Александров имел огромный авторитет и у маститых ученых, и у молодежи. "Он руководил университетом не силой приказа, а моральным авторитетом", - отметил В. И. Смирнов (1887-1974) в адресе, написанном по случаю ухода Александрова с поста ректора.

В 1964 г. по приглашению М. А. Лаврентьева (1900-1980) Александров переехал с семьей в Новосибирск, где нашел много верных друзей и учеников и до 1986 г. возглавлял один из отделов Института математики, преподавал в НГУ и разработал новые варианты школьных учебников по геометрии. Сибири Александров отдал не только душу и сердце, но и здоровье, перенеся клещевой энцефалит. С апреля 1986 г. до своей кончины 27 июля 1999 г. Александров работал в Санкт-Петербургском отделении Математического института им. В. А. Стеклова. 
Делом жизни Александрова была геометрия. В самом начале своей научной карьеры он получил очень интересные и глубокие результаты по теории смешанных объемов выпуклых тел. Александров доказал фундаментальные теоремы о выпуклых многогранниках, стоящие в одном ряду с теоремами Эйлера и Минковского. Значение вклада Александрова в теорию Брунна-Минковского была широко осознано спустя 40 лет после их появления, когда в 1970-х годах прояснилась как связь неравенства Александрова-Фенхеля с неравенством Ходжа для индексов пересечения алгебраических кривых, так и роль смешанных объемов при изучении многогранников Ньютона. И сегодня статьи Александрова, посвященные этой теме, поражают мастерством изложения и выглядят вполне современно. Без малейших колебаний их можно было бы напечатать в любом математическом журнале прямо сейчас.

Одно из основных научных открытий Александрова - его решение знаменитой проблемы Вейля о реализации гомеоморфного сфере двумерного риманова многообразия положительной гауссовой кривизны в виде выпуклой поверхности в трехмерном пространстве. План решения этой проблемы, предложенный самим Вейлем, был чисто аналитическим - требовалось только доказать некоторые оценки для дифференциальных уравнений. За время, прошедшее с тех пор, математика научилась отыскивать такие оценки, и сегодня можно считать проблему Вейля многократно решенной, в частности, и на пути, указанном Вейлем.

Александров предложил чисто геометрический подход к решению проблемы Вейля. Сначала рассматривается некоторый аналог проблемы для многогранников, относящийся фактически к элементарной геометрии. С помощью предельного перехода затем получается решение задачи в общем виде. Именно этот путь привел Александрова к созданию нового направления, которое можно характеризовать как нерегулярную риманову геометрию.

Классическая дифференциальная геометрия обычно рассматривает геометрические образы, удовлетворяющие определенным условиям регулярности, т. е. такие, которые могут быть описаны с помощью достаточно гладких функций. Во многих задачах это требование является чрезмерно ограничительным. Более того, существуют задачи, которые не имеют решения при предположениях регулярности, устанавливаемых в дифференциальной геометрии, и становятся разрешимыми, если эти условия ослабить. Примеры задач такого рода были Александровым указаны. Заметим еще, что даже объекты, определяемые вполне классическим путем, могут нести на себе особенности и, более того, строение объекта в целом определяется характером его особых точек или линий.

K нерегулярной римановой геометрии относятся исследования Александрова по теории двумерных многообразий ограниченной кривизны. В этой области им и его учениками получены вполне законченные результаты. В классической - гауссовой внутренней геометрии поверхностей определены понятия длины кривой, понятие кратчайшей, понятие угла между кривыми, исходящими из одной точки, понятие геодезической кривизны кривой и, наконец, понятия площади множества на поверхности и гауссовой кривизны в точке поверхности. Все эти понятия имеют свой аналог и в общей теории поверхностей, построенной Александровым - теории двумерных многообразий ограниченной кривизны. Вместо гауссовой кривизны в точке Александров рассматривает интегральную кривизну множества. В регулярном случае интегральная кривизна множества есть интеграл от гауссовой кривизны относительно площади. Для общих многообразий ограниченной кривизны интегральная кривизна, как функция множества, может не быть абсолютно непрерывной относительно площади.

Примером двумерного многообразия ограниченной кривизны может служить любая двумерная многогранная поверхность. В этом случае интегральная кривизна сосредоточена на дискретном множестве - множестве вершин многогранника. Если $\theta(X)$ есть полный угол в некоторой вершине многогранника, т. е. сумма углов граней 
многогранника, имеющих вершиной точку $X$, то интегральная кривизна множества, состоящего из единственного элемента - точки $X$, равна разности $2 \pi-\theta(X)$, в каждой вершине поверхности куба сосредоточена интегральная кривизна равная $\pi / 2$.

Другой пример - поверхность прямого кругового цилиндра, включая его боковую поверхность и два основания. Это есть двумерное многообразие ограниченной кривизны, причем интегральная кривизна сосредоточена на множестве, образованном двумя окружностями, ограничивающими верхнее и нижнее основания цилиндра. Еще один пример - поверхность, образованная касательными регулярной кривой $K$. Со студенческой скамьи известно, что это есть развертывающаяся поверхность, малый кусок который изометричен плоской области. Однако, если рассмотреть строение этой поверхности в целом, мы увидим, что на ней есть особая линия - кривая $K$, касательные к которой образуют данную поверхность. С учетом этого обстоятельства получаем, что поверхность касательных есть двумерное многообразие ограниченной кривизны в смысле Александрова. Интегральная кривизна множества на поверхности касательных равна нулю, если это множества не содержит точек кривой $K$. Если множество пересекается с кривой $K$ по некоторой дуге, то интегральная кривизна множества равна взятому со знаком минус удвоенному интегралу по этой дуге от кривизны кривой относительно длины.

Александровым было дано два альтернативных определения понятия двумерного многообразия ограниченной кривизны. Одно определение - аксиоматическое. Другое - аппроксимативное. Пусть дано двумерное многообразие, на котором задана некоторая внутренняя метрика. Тогда, по Александрову, говорят, это есть метрика ограниченной кривизны, если в окрестности произвольной точки многообразия можно построить равномерно сходящуюся к ней на этой окрестности последовательность римановых метрик (т. е. метрик, каждая из которых порождается некоторым гауссовым линейным элементом), удовлетворяющих дополнительному условию: интегралы от модуля гауссовых кривизн этих римановых метрик не превосходят некоторой постоянной.

Аксиоматическое и аппроксимативное определения двумерного многообразия ограниченной кривизны затем были усовершенствованы В. А. Залгаллером, который показал возможность ослабить некоторые условия в первоначальных определениях Александрова. Достаточно требовать ограниченность интегралов от положительной части гауссовой кривизны. В многомерном случае аналоги теории двумерных многообразий ограниченной кривизны не построены. Это связано с тем, что даже в регулярном случае теория кривизны для многомерного случая оказывается существенно сложнее, чем в двумерном случае. Поэтому следует ожидать, что многомерный аналог понятия двумерного многообразия ограниченной кривизны не может быть определен однозначно. В многомерном случае Александровым были введены понятия метрических пространств кривизны, ограниченной сверху или снизу некоторой постоянной, фиксированной для данного пространства $K$, и построена теория пространств кривизны, не большей $K$.

Пусть $K$ - вещественное число. Символом $S_{K}$ будем обозначать поверхность постоянной кривизны, равной $K$. В случае $K>0$ поверхность $S_{K}$ есть сфера радиуса $1 / \sqrt{K}$, в случае $K=0$ поверхность $S_{K}$ есть обычная евклидова плоскость и, наконец, в случае $K<0$ поверхность $S_{K}$ есть плоскость Лобачевского с кривизной, равной $K$. Определение пространства кривизны, не большей $K$ или не меньшей $K$, по Александрову основывается на следующем построении. Пусть дано метрическое пространство $M$, и пусть $A B C$ есть произвольный треугольник в этом пространстве, т. е. система, состоящая из трех точек $A, B$ и $C$ и трех кратчайших $A B, B C$ и $C A$, соединяющих эти точки. На плоскости $S_{K}$ построим треугольник $A^{\prime} B^{\prime} C^{\prime}$, для которого $\left|A^{\prime} B^{\prime}\right|=|A B|,\left|B^{\prime} C^{\prime}\right|=|B C|$ и, далее, $\left|C^{\prime} A^{\prime}\right|=|C A|$. Пусть $\alpha_{K}, \beta_{K}$ и $\gamma_{K}$ суть углы треугольника $A^{\prime} B^{\prime} C^{\prime}$ в точках $A^{\prime}, B^{\prime}$ и $C^{\prime}$ соответственно. Треугольник $A^{\prime} B^{\prime} C^{\prime}$ 
называется разверткой треугольника $A B C$ на поверхности $S_{K}$ постоянной кривизны, равной $K$.

Предположим, что метрическое пространство $M$ является римановым пространством, удовлетворяющим условию: секционная кривизна в каждой точке пространства в любом двумерном направлении не превосходит числа $K$. Пусть $A B C$ - произвольный геодезический треугольник в пространстве $M, \alpha, \beta$ и $\gamma-$ углы между его сторонами в точках $A, B$ и $C$ соответственно. Тогда имеет место неравенство

$$
\alpha+\beta+\gamma \leqslant \alpha_{K}+\beta_{K}+\gamma_{K} .
$$

Аналогично, если секционная кривизна риманова пространства в каждой точке ограничена снизу числом $K$, то имеет место неравенство

$$
\alpha+\beta+\gamma \geqslant \alpha_{K}+\beta_{K}+\gamma_{K} .
$$

Это свойство римановых пространств и берется за основу при определении того, что данное метрическое пространство есть пространство кривизны, ограниченной сверху или ограниченной снизу числом $K$.

Пространства ограниченной снизу кривизны, $A^{+}$, и пространства ограниченной сверху кривизны, $A^{-}$, играют в современной геометрии колоссальную роль. Александров в соответствии со своими научными вкусами и предпочтениями в первую очередь акцентировал внимание на аксиоматику этих классов, что не помешало ему получить о них ряд превосходных результатов. Класс $A^{+}$начал интенсивно изучаться в 1990-х годах, причем был достигнут большой прогресс. Содержательная теория пространств класса $A^{-}$была получена значительно раньше, однако только в случае неположительной кривизны, так как только в этом случае ограничение на кривизну сверху влечет содержательные свойства пространства в целом. Таковы пространства Адамара и их факторы по группам изометрии. Немного особняком стоят так называемые "обобщенные римановы многообразия", также введенные Александровым. Их теория была построена В.Н. Берестовским и И.Г. Николаевым, доказавшими, что пересечение $A^{+} \cap A^{-}$при некоторых естественных ограничениях состоит из римановых многообразий, метрические тензоры которых имеют пониженную по сравнению с классической теорией гладкость. Александрова, наряду с С.Э. Кон-Фоссеном и $\mathrm{X}$. Хопфом, следует считать одним из основоположников метрической геометрии.

Риманова геометрия не была самой главной темой творчества Александрова, однако именно его работы оказали большое влияние на ее современный облик. Риманова геометрия 1930-1940-х годов была почти полностью локальной теорией, а книги в этой области представляли собой собрания громоздких формул, без рисунков и четких указаний степени гладкости. Современная риманова геометрия стала "геометрией в целом" в основном под влиянием пионерских работ Александрова, Э. Картана, Г. Рауха, В. Клингенберга и др. Александров дал развитие геометрической концепции пространства, и в этом непреходящее значение его работ по римановой геометрии.

Большой цикл работ был выполнен Александровым по хроногеометрии - направлению, занимающемуся вопросами геометрических оснований теории относительности. Ему принадлежат исследования в теории меры, теории уравнений в частных производных, в кристаллографии, и этот список далеко не полон.

Понять мировоззрение Александрова невозможно без обращения к корням его любимой науки. "Пафос современной математики в том, что происходит возврат к грекам", - писал он в 1981 г. Любимый лозунг Александрова - "Назад, к Евклиду!". Геометрия - часть культуры древнего мира.

Знаменитые гарпедонапты Египта были налоговыми служащими, использовавшими веревку для обмера земельных наделов. Навыки гарпедонаптов применялись и в строительстве. Пирамиды построены задолго до их геометрического определения. 
Выдающимся открытием греческой геометрии стала несоизмеримость стороны и диагонали квадрата. Обнаружив отсутствие общей меры у стороны и диагонали квадрата, наши предки выяснили, что рациональных чисел недостаточно для практических измерений. Открытие несоизмеримости стороны и диагонали квадрата - такая же высочайшая вершина математики, как независимость пятого постулата, аксиомы выбора или гипотезы континуума. Логика Аристотеля следовала за геометрией и отражала ее методологию.

Александров осуществил поворот к синтетической геометрии древних в гораздо более тонком смысле, чем это теперь понимают. Речь идет не просто о переходе от гладкой локальной геометрии к геометрии в целом без ограничений дифференцируемости. Расширяя методы дифференциальной геометрии аппаратом функционального анализа и теории меры, Александров стремился к состоянию математики во времена Евклида. Синтезируя геометрию с другими разделами математики XX века, Александров восходил к античному идеалу единой науки.

Александров не только преодолел многие локальные ограничения дифференциальной геометрии поверхностей, основанной на инфинитезимальных методах и идеях Ньютона, Лейбница и Гаусса, но и обогатил геометрию аппаратом функционального анализа, теории меры и уравнений математической физики. Начатый Александровым поворот к синтетическим методам был неизбежен, что иллюстрируют результаты учеников и продолжателей идей Александрова.

Геометрия возникла в результате практической деятельности человека, она создана человеком для того, чтобы организовать собственную жизнь и изменить ее к лучшему. Человек - исходный пункт, творец и цель жизни. Общие воззрения Александрова определялись его естественно-научными взглядами, сложившимися при изучении геометрии, он оставил нам обширное наследство в области публицистики, отразившей его взгляды на жизнь науки и общества. Александрову весьма импонировали идеи К. Маркса, выраженные в тезисах о Фейербахе.

Александров не был человеком прошлого, но прошлого не стеснялся. Умел видеть собственные заблуждения и отказываться от них. Не прятал свои ошибки и старался их выправить по мере возможности. Интересовался не тем, кто чем занимается, а кто что сделал. Не кичился сам ничем и ненавидел дурной меритократизм. Был динамичен и принципиален по отношению к истине. Каждый сам себе доверяет невзирая на лукавые оговорки. Александров умел распространять практику доверия на других, исходя из презумпции порядочности, которая действует до первого сбоя. Сам Александров был человеком чести, чьи свидетельства можно принимать как собственные без доказательств. Александров ставил доверие выше доказательств.

Синтезируя геометрию с прочими разделами математики, Александров восходил к античному идеалу единой науки и помещал научность в центр своих этических воззрений. Размышления о нравственности Александрова связаны с противопоставлением религиозной веры и научного поиска. Не идеальная абстракция, а реальный человек со своими земными заботами стоит в центре его этики. Человек, ищущий истину, - творец обстоятельств жизни, ее источник и цель. Для Александрова важны как открытость науки, так и ее принципиальный отказ от любых форм догматизма и субъективизма, присущих вере.

Ненависть Александрова вызывали любые проходимцы, попы и инквизиторы от "марксизма", использующие науку в низких корыстных целях. Между наукой и властью лежит пропасть отчуждения. Власть противостоит свободе, составляющей сущность математики. В науке Александров видел инструмент, который освобождает человека материально и раскрепощает его интеллектуально. Геометрия учила Александрова универсальному гуманизму. Он любил слова апостола Павла и повторял, что в геометрии "нет ни Еллина, ни Иудея". Человечность, ответственность и научность - таковы составляющие полноты нравственности по Александрову. Человек - 
источник и цель всего. Таково содержание универсального гуманизма. Человек - в ответе за все. Таков смысл ответственности. Научность, как человеческое суждение, отвлеченное от субъективизма, лежит в основе нравственности. Твердые принципы Александрова делали предсказуемой и трагичной его судьбу. Защита истины тяжелый крест, одинокое служение.

Александров часто подвергался несправедливым нападкам за свои убеждения и ощущал себя "рыжим у ковра". Непонимание и глумление - удел героя при жизни. В годы перестройки Александрова обвинили в лысенкоизме и наградили орденом за вклад в сохранение и развитие отечественной генетики и селекции. Таков был масштаб личности этого человека.

Время ставит все на свои места - Александров остался в истории выдающимся геометром и верным рыцарем науки.

С.С. Кутателадзе, С.П. Новиков, Ю.Г. Решетняк 